\title{
Seroprevalence and associated risk factors of Toxoplasma gondii infection in patients undergoing hemodialysis and healthy group
}

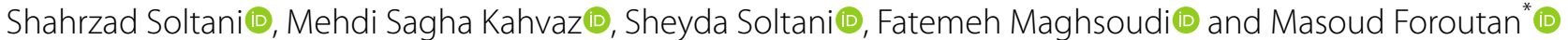

\begin{abstract}
Objectives: In this study, the seroprevalence of anti-Toxoplasma gondii (T. gondii) specific antibodies in patients undergoing hemodialysis compared to the control group were evaluated. In this case-control study, 200 hemodialysis patients (HDP) and 100 healthy controls were participated. The specific antibodies (lgG/lgM) in both groups were tested using enzyme-linked immunosorbent assay (ELISA) method. A structured questionnaire containing some demographic information was completed for each person in case and control groups.

Results: The overall seroprevalence of T. gondii infection was 49.5\% (99/200) and 23.0\% (23/100) in the case and control groups, respectively. There was a significant association between seroprevalence of $T$. gondii infection and contact with cats $(P<0.001)$, consumption of raw/undercooked meat $(P=0.01)$, and source of drinking water $(P=0.001)$ in the hemodialysis patients. Also, in the control subjects, there were a significant association between consumption of raw/ undercooked meat $(P=0.04)$ and source of drinking water $(P=0.001)$ with $T$. gondii infection. The findings showed a high seroprevalence of T. gondii infection in HDP compared with healthy controls; thus, we recommend the regular screening programs for T. gondii infection in this susceptible group.
\end{abstract}

Keywords: Toxoplasma gondii, Hemodialysis, Seroprevalence, ELISA, Iran

\section{Introduction}

Toxoplasma gondii (T. gondii) is the well-known intracellular parasite with widespread distribution in all continents which could infect a broad range of warm-blooded vertebrates $[1,2]$. T. gondii infection is mainly transmitted through ingestion of oocyst-contaminated food or water, ingestion of raw/undercooked meat contaminated with tissue cysts, consumption of raw/unwashed vegetables, vertical transmission from mother to the fetus and rarely by organ transplantation and blood transfusion [3-7].

It is estimated that approximately one-third of the human population is chronically infected throughout the globe $[3,4,8]$. The previously articles with meta-analysis

*Correspondence: masoud_foroutan_rad@yahoo.com

USERN Office, Abadan Faculty of Medical Sciences, Abadan, Iran approach in Iran have reported the pooled seroprevalence rate of $T$. gondii infection in different human groups. For example, in some groups such as HIV-positive subjects, patients with malignancy, transplant recipients, general population, pregnant women, healthy blood donors, and hemodialysis patients (HDP), the seroprevalence rate was estimated to be $50 \%, 45 \%, 55 \%, 39 \%, 41 \%$, $34 \%$, and $58 \%$, respectively [9-13].

Although, toxoplasmosis is sometimes asymptomatic in immunocompetent persons, it can cause severe complications or even may result in death in the immunocompromised subjects [3]. As it is evident, the patients undergoing hemodialysis are considered to be immunocompromised, mainly due to immune response dysfunctions regarding phagocytosis, chemotaxis, and the complement system [14]; thus, these subjects are more susceptible than healthy individuals to acquire several

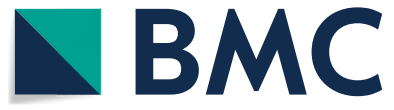

(c) The Author(s) 2020. This article is licensed under a Creative Commons Attribution 4.0 International License, which permits use, sharing, adaptation, distribution and reproduction in any medium or format, as long as you give appropriate credit to the original author(s) and the source, provide a link to the Creative Commons licence, and indicate if changes were made. The images or other third party material in this article are included in the article's Creative Commons licence, unless indicated otherwise in a credit line to the material. If material is not included in the article's Creative Commons licence and your intended use is not permitted by statutory regulation or exceeds the permitted use, you will need to obtain permission directly from the copyright holder. To view a copy of this licence, visit http://creativeco mmons.org/licenses/by/4.0/. The Creative Commons Public Domain Dedication waiver (http://creativecommons.org/publicdomain/ zero/1.0/) applies to the data made available in this article, unless otherwise stated in a credit line to the data. 
opportunistic microorganisms, such as $T$. gondii [13, 15]. The current investigation was aimed to evaluate the prevalence of anti-T. gondii specific antibodies in patients undergoing hemodialysis in comparison to control groups.

\section{Methods}

In this case-control study, 200 HDP who were referred to Shahid Beheshti and Valiasr hospitals affiliated to the Abadan Faculty of Medical Sciences in the southwest Iran (Khuzestan Province, between 2018 and 2019) and 100 healthy controls were enrolled and venous blood samples were collected from all participants. The inclusion criteria were as follows: (1) subjects $\geq 10$ years old; (2) volunteer to participate in the study upon obtaining a written informed consent; (3) in case group: the patients undergoing regular hemodialysis; and (4) in the control group: healthy volunteers with normal blood urea nitrogen and creatinine levels as well as without any renal disease. It should be noted that the subjects were matched in terms of gender and age in both groups.

A structured questionnaire containing some demographic information was developed and accomplished for each person in case and control groups, as previously described [16, 17]. The demographic information and related risk factors with $T$. gondii infection were as follows: gender, age, residence, education level, contact with cats, consumption of raw/undercooked meat, and source of drinking water.

From each participant who have met the inclusion criteria, $5 \mathrm{~mL}$ of venous blood was taken and then the samples were transferred to the laboratory of the Abadan Faculty of Medical Sciences. As earlier described [17], the sera were separated by centrifugation at $1700 \times g$ for $5 \mathrm{~min}$ and then stored in $-20^{\circ} \mathrm{C}$ till examined. The specific antibodies (IgG/IgM) in both groups were measured using commercial available enzyme-linked immunosorbent assay kits (Torch-IgG, IgM-Trinity Biotech Company), according to the manufacturer's guideline. The Chi-square test was performed using SPSS version 21 (SPSS Inc., Chicago, IL, USA). Also, we used Univariate logistic regression analysis to assess the probable association between the related risk factors and seropositivity of T. gondii infection. The level of significance was considered $P<0.05$ [16].

\section{Results}

The main characteristics and seroprevalence of T. gondii infection of the participants in case and control groups are listed in Table 1. Briefly, the overall seroprevalence of T. gondii infection was estimated to be $49.5 \%$ (99/200) and $23.0 \%(23 / 100)$ in the case and control groups, respectively. Of these, anti- $T$. gondii IgG antibodies were found in 40.0\% (80/200) of HDP and 21.0\% (21/100) of healthy controls, while IgM were identified in $9.5 \%$ $(19 / 200)$ and $2.0 \%(2 / 100)$ of these groups, respectively $(P<0.05)$. Upon analysis, HDP were significantly more likely to be seropositive for IgG (OR, 2.50; 95\% CI 1.434.38; $P<0.001)$ and IgM (OR, 5.14; 95\% CI 1.17-22.54; $P<0.016)$ antibodies against $T$. gondii infection than healthy volunteers.

In this study, we have recorded seven probable risk factors associated with $T$. gondii infection. There was a significant association between seroprevalence of $T$. gondii infection and contact with cats (OR 3.73 [95\% CI 2.00-6.95]; $P<0.001)$, consumption of raw/undercooked meat (OR 2.04 [95\% CI 1.14-3.63]; $P=0.01$ ), and source of drinking water (OR 3.07 [95\% CI 1.59-5.95]; $P=0.001)$ in the hemodialysis patients. Also, in the control subjects, there were a significant association between consumption of raw/undercooked meat (OR 2.71 [95\% CI 1.017.26]; $P=0.04)$ and source of drinking water (OR 5.54 [95\% CI 1.82-16.86]; $P=0.001$ ) with $T$. gondii infection. More details are shown in Table 1.

\section{Discussion}

During the two past decades, an increasing trend was reported in the number of persons with renal failure and end-stage renal disease requiring hemodialysis [18]. There is a lack of knowledge about the epidemiological status of T. gondii infection in rural and urban communities of southwest Iran amongst patients undergoing hemodialysis. Thus, in the current study, we evaluated the seroprevalence of anti- $T$. gondii antibodies in HDP compared to control group from these regions. The results showed that the seroprevalence rate of $T$. gondii infection was higher in patients undergoing hemodialysis than normal subjects (49.5\% vs. $23.0 \%)$. Our findings were in accordance with previous studies such as Ebrahim Zadeh in Zahedan city (Sistan and Baluchistan province) [19], Solhjoo et al. in Jahrom city (Fars province) [20], Bayani et al. in Babol city (Mazandaran province) [21], Saadat et al. in Rasht city (Guilan province) [22], Arefkhah et al. in Boyer-Ahmad city (Kohgiluyeh and Boyer-Ahmad province) [16], Saki et al. in Ahvaz city (Khuzestan province) [23], and Hamidi et al. in East Azerbaijan province [24].

In case group, $40.0 \%$ and $9.5 \%$ of HDP were found positive for IgG and IgM antibodies using ELISA, respectively. This seroprevalence rate of latent infection is similar with Khalili et al. study in Chaharmahal and Bakhtiari province $(45.0 \%)$ [25]. In the majority of studies in different parts of Iran such as Tehran (60.0\%) [26], Sistan and Baluchistan (73.7\%) [27], East Azerbaijan (70.2\%) [24], Guilan (72.0\%) [22], Mazandaran (80.0\%) [21], Isfahan and Qom provinces (63.0\%) [28], the seropositivity in patients 
Table 1 Seroprevalence of Toxoplasma gondii infection in HDP and healthy controls [ $\boldsymbol{n}(\%)$ ]

\begin{tabular}{|c|c|c|c|c|c|c|c|c|c|c|}
\hline \multirow[t]{3}{*}{ Characteristic } & \multicolumn{5}{|c|}{ Hemodialysis patients } & \multicolumn{5}{|c|}{ Control group } \\
\hline & \multirow[t]{2}{*}{ Number tested } & \multirow[t]{2}{*}{ Seropositive, n (\%) } & \multicolumn{3}{|c|}{ Univariate analysis } & \multirow{2}{*}{$\begin{array}{l}\text { Number } \\
\text { tested }\end{array}$} & \multirow[t]{2}{*}{ Seropositive, n (\%) } & \multicolumn{3}{|c|}{ Univariate analysis } \\
\hline & & & OR & $95 \% \mathrm{Cl}$ & $P$ value & & & OR & $95 \% \mathrm{Cl}$ & $P$ Value \\
\hline \multicolumn{11}{|l|}{ Gender } \\
\hline Male & 105 & $54(51.42)$ & 0.85 & $0.48-1.48$ & 0.56 & 53 & $12(22.64)$ & 1.04 & $0.41-2.65$ & 0.92 \\
\hline Female & 95 & $45(47.36)$ & 1.17 & $0.67-2.05$ & & 47 & $11(23.40)$ & 0.95 & $0.37-2.43$ & \\
\hline \multicolumn{11}{|l|}{ Age } \\
\hline$\leq 20$ & 15 & $7(46.66)$ & 1.00 & Referent & 0.99 & 10 & $1(10.00)$ & 1.00 & Referent & 0.99 \\
\hline $21-40$ & 35 & $16(45.71)$ & 1.039 & $0.30-3.49$ & & 19 & $4(21.05)$ & 0.75 & $0.07-8.08$ & \\
\hline $41-60$ & 60 & $29(48.33)$ & 0.935 & $0.30-2.90$ & & 25 & $7(28.00)$ & 0.429 & $0.04-4.23$ & \\
\hline $61-80$ & 76 & $40(52.63)$ & 0.788 & $0.26-2.38$ & & 37 & $8(21.62)$ & 0.604 & $0.06-5.77$ & \\
\hline $81-90$ & 14 & $7(50.00)$ & 0.875 & $0.20-3.76$ & & 9 & $3(33.33)$ & 0.333 & $0.02-4.18$ & \\
\hline \multicolumn{11}{|l|}{ Residence } \\
\hline Urban & 147 & $76(51.70)$ & 1.39 & $0.74-2.62$ & 0.30 & 72 & $17(23.61)$ & 1.13 & $0.39-3.25$ & 0.81 \\
\hline Rural & 53 & $23(43.39)$ & 0.71 & $0.38-1.34$ & & 28 & $6(21.42)$ & 0.88 & $0.30-2.53$ & \\
\hline \multicolumn{11}{|l|}{ Education level } \\
\hline Diploma or lower & 154 & $80(51.94)$ & 1.53 & $0.78-2.99$ & 0.20 & 75 & $19(25.33)$ & 1.78 & $0.54-5.85$ & 0.33 \\
\hline University degree & 46 & $19(41.30)$ & 0.65 & $0.33-1.26$ & & 25 & $4(16.00)$ & 0.56 & $0.17-1.84$ & \\
\hline \multicolumn{11}{|l|}{ Contact with cat } \\
\hline Yes & 70 & $49(70.00)$ & 3.73 & $2.00-6.95$ & $<0.001$ & 33 & $10(30.30)$ & 1.80 & $0.69-4.70$ & 0.22 \\
\hline No & 130 & $50(38.46)$ & 0.26 & $0.14-0.49$ & & 67 & $13(19.40)$ & 0.55 & $0.21-1.44$ & \\
\hline \multicolumn{11}{|c|}{ Consumption of raw/undercooked meat } \\
\hline Yes & 78 & $47(60.25)$ & 2.04 & $1.14-3.63$ & 0.01 & 27 & $10(37.03)$ & 2.71 & $1.01-7.26$ & 0.04 \\
\hline No & 122 & $52(42.62)$ & 0.49 & $0.27-0.87$ & & 73 & $13(17.80)$ & 0.36 & $0.13-0.98$ & \\
\hline \multicolumn{11}{|c|}{ Source of drinking water } \\
\hline Sanitary water & 145 & $61(42.06)$ & 0.32 & $0.16-0.62$ & 0.001 & 83 & $14(16.86)$ & 0.18 & $0.05-0.54$ & 0.001 \\
\hline Unsanitary water & 55 & 38 (69.09) & 3.07 & $1.59-5.95$ & & 17 & 9 (52.94) & 5.54 & $1.82-16.86$ & \\
\hline
\end{tabular}

HDP hemodialysis patients, $\mathrm{OR}$ odds ratio, $\mathrm{Cl}$ confidence interval

undergoing hemodialysis were reported over $60 \%$, while the lower seroprevalence rate of $T$. gondii infection was reported by Saki et al. from Khuzestan province (29.3\%) [23] and Arefkhah et al. from Kohgiluyeh and BoyerAhmad province (27.7\%) [16]. The disagreement between studies is may be due to several reasons, including, study area, the number of participants, type of sampling, methodology, cultural habits of the subjects, different cutoff values or antibody titers and so on.

In a comprehensive systematic review with meta-analysis approach that performed by Foroutan et al. [13] in Iran, the pooled seroprevalence of latent and acute $T$. gondii infection in patients undergoing hemodialysis was evaluated up to December 2017. Finally, 1865 individuals (1048 HDP and 817 normal subjects as controls) were eligible to be included. The results revealed that $58 \%$ (95\% CI 46-70\%) and 40\% (95\% CI 31-50\%) of HDP and healthy controls were seropositive in terms of IgG, while IgM antibody were detected in $2 \%(95 \%$ CI $0-6)$ and $0 \%$ (95\% CI $0-1)$ of these groups, respectively. They concluded that patients undergoing hemodialysis were more likely to be seropositive for IgG $(\mathrm{OR}=2.04 ; 95 \%$ CI 1.54 $2.70 ; P<0.001)$ and $\operatorname{IgM}(\mathrm{OR}=2.53$; $95 \%$ CI $1.23-5.22$; $P<0.001)$ antibodies against Toxoplasma infection than healthy volunteers. Also, the latent infection ranged from 29 to $80 \%$ with the highest prevalence in Mazandaran province [13]. Also, it is worth to mention that in two different systematic reviews among the Iranian general population (approximately 59\%) and pregnant women (ranged from 56 to $75 \%$ ), Mazandaran province revealed one of the highest seroprevalence rate of $T$. gondii infection throughout the country $[10,11]$. It seems the climate status of this province is an important parameter. Mazandaran province has ideal mean humidity and annual rainfall, which considered as suitable conditions for $T$. gondii oocysts sporulation. Also, the cultural habits of the people and working on farming lands may be the other reasons [10].

The results of our study showed that there was a significant association between $T$. gondii seroprevalence and consumption of raw/undercooked meat and source of drinking water in both case and control groups. Belluco 
et al. [29] have confirmed that different meat products are considered as the main sources for acquiring the infection. So, they concluded that the increase in consumer knowledge definitely could influence in the reduction of the infection rate in societies $[6,29]$.

\section{Conclusions}

In conclusion, our investigation showed a high seroprevalence of $T$. gondii infection in patients undergoing hemodialysis compared with healthy controls in southwest Iran. Since, these patients are immunocompromised and toxoplasmosis may cause severe and progressive complications with very poor prognosis in such patients, we recommend the regular screening programs for $T$. gondii infection into the routine clinical care of patients undergoing hemodialysis.

\section{Limitations}

In this study, the only ELISA assay was performed on collected sera with no supporting data by molecular confirmation. As evident, it would have been ideal to perform PCR technique on IgM positive samples by ELISA, but this point was not possible due to financial constraints. On the other hands, the PCR technique is used when the patient is in the acute stage and the tachyzoites are in the bloodstream. Since this step is very short, therefore PCR only responds to patients who are positive for IgM and is mostly used for immunocompromised subjects.

\section{Abbreviations \\ ELISA: Enzyme-linked immunosorbent assay; HDP: Hemodialysis patients; IgG: Immunoglobulin G; IgM: Immunoglobulin M; T. gondii: Toxoplasma gondii.}

\section{Acknowledgements}

The authors sincerely appreciate all personnel of Shahid beheshti and Valiasr hospitals in Abadan and Khorramshahr cities for their kind cooperation.

\section{Authors' contributions}

SS and MF conceived, designed and drafted the manuscript; SHS and MSK involved in data acquisition; FM involved in statistical analysis; MF critically revised the text. All authors read and approved the final version of the manuscript.

\section{Funding}

This study was financially supported by Abadan Faculty of Medical Sciences, Abadan, Iran (Grant No. 97U-547).

\section{Availability of data and materials}

The datasets used and/or analysed during the current study available from the corresponding author on reasonable request.

\section{Ethics approval and consent to participate}

All subjects voluntarily agreed to be tested. A written informed consent was obtained from adult persons and parent or guardian of subjects less than 18 years old. This study received the approval from the Abadan Faculty of Medical Sciences Ethical Committee (IR.ABADANUMS.REC.1397.017).

\section{Consent for publication}

Not applicable.

\section{Competing interests}

The authors declare that there is no conflict of interest.

Received: 26 September 2020 Accepted: 24 November 2020

Published online: 07 December 2020

\section{References}

1. Dubey JP. The history of Toxoplasma gondii-the first 100 years. J Eukaryot Microbiol. 2008;55:467-75.

2. Foroutan M, Fakhri Y, Riahi SM, Ebrahimpour S, Namroodi S, Taghipour A, et al. The global seroprevalence of Toxoplasma gondii in pigs: a systematic review and meta-analysis. Vet Parasitol. 2019;269:42-52.

3. Wang ZD, Liu HH, Ma ZX, Ma HY, Li ZY, Yang ZB, et al. Toxoplasma gondii infection in immunocompromised patients: a systematic review and meta-analysis. Front Microbiol. 2017;8:389.

4. Foroutan-Rad M, Majidiani H, Dalvand S, Daryani A, Kooti W, Saki J, et al. Toxoplasmosis in blood donors: a systematic review and meta-analysis. Transfus Med Rev. 2016;30:116-22.

5. Fallahi S, Rostami A, Nourollahpour Shiadeh M, Behniafar H, Paktinat S. An updated literature review on maternal-fetal and reproductive disorders of Toxoplasma gondii infection. J Gynecol Obstet Hum Reprod. 2018;47:133-40.

6. Belluco S, Simonato G, Mancin M, Pietrobelli M, Ricci A. Toxoplasma gondii infection and food consumption: a systematic review and meta-analysis of case-controlled studies. Crit Rev Food Sci Nutr. 2018;58:3085-96.

7. Foroutan M, Zaki L, Tavakoli S, Soltani S, Taghipour A, Ghaffarifar F. Rhomboid antigens are promising targets in the vaccine development against Toxoplasma gondii. EXCLI J. 2019;18:259-72.

8. Rostami A, Riahi SM, Gamble HR, Fakhri Y, Nourollahpour Shiadeh M, Danesh $M$, et al. Global prevalence of latent toxoplasmosis in pregnant women: a systematic review and meta-analysis. Clin Microbiol Infect. 2020;26:673-83.

9. Ahmadpour E, Daryani A, Sharif M, Sarvi S, Aarabi M, Mizani A, et al. Toxoplasmosis in immunocompromised patients in Iran: a systematic review and meta-analysis. J Infect Dev Ctries. 2014;8:1503-10.

10. Daryani A, Sarvi S, Aarabi M, Mizani A, Ahmadpour E, Shokri A, et al. Seroprevalence of Toxoplasma gondii in the Iranian general population: a systematic review and meta-analysis. Acta Trop. 2014;137:185-94.

11. Foroutan-Rad M, Khademvatan S, Majidiani H, Aryamand S, Rahim F, Malehi AS. Seroprevalence of Toxoplasma gondii in the Iranian pregnant women: a systematic review and meta-analysis. Acta Trop. 2016;158:160-9.

12. Mansouri A, Adhami Mojarad MR, Badfar G, Abasian L, Rahmati S, Kooti W, et al. Epidemiology of Toxoplasma gondii among blood donors in Iran: a systematic review and meta-analysis. Transfus Apher Sci. 2017;56:404-9.

13. Foroutan M, Rostami A, Majidiani H, Riahi SM, Khazaei S, Badri M, et al. A systematic review and meta-analysis of the prevalence of toxoplasmosis in hemodialysis patients in Iran. Epidemiol Health. 2018;40:e2018016.

14. Kato S, Chmielewski M, Honda H, Pecoits-Filho R, Matsuo S, Yuzawa Y, et al. Aspects of immune dysfunction in end-stage renal disease. Clin J Am Soc Nephrol. 2008;3:1526-33.

15. Omrani VF, Fallahi S, Rostami A, Siyadatpanah A, Barzgarpour G, Mehravar $S$, et al. Prevalence of intestinal parasite infections and associated clinical symptoms among patients with end-stage renal disease undergoing hemodialysis. Infection. 2015:43:537-44.

16. Arefkhah N, Hosseini SA, Karimzade R, Moshfe A, Hadinia F, Larki RA, et al. Seroprevalence and risk factors of Toxoplasma gondii infection among cancer and hemodialysis patients in southwest Iran. Clin Epidemiol Glob Health. 2019;7:596-9.

17. Soltani S, Foroutan M, Afshari H, Hezarian M, Kahvaz MS. Seroepidemiological evaluation of Toxoplasma gondii immunity among the general population in southwest of Iran. J Parasit Dis. 2018;42:636-42.

18. Kurella TM. Incidence, management, and outcomes of end-stage renal disease in the elderly. Curr Opin Nephrol Hypertens. 2009;18:252-7.

19. Ebrahim Zadeh A, Bamedi T, Etemadi S, Shahrakipour M, Saryazdipour K. Toxoplasmosis as a complication of transfusion in hemodialysis patients. Iran J Pediatr Hematol Oncol. 2014;4:22-5.

20. Solhjoo K, Jahromi A, Parnian-Rad A. Anti-Toxoplasma gondii antibodies in haemodialysis patients. Am J Infec Dis. 2010;6:13-7. 
21. Bayani M, Mostafazadeh A, Oliaee F, Kalantari N. The Prevalence of Toxoplasma gondii in hemodialysis patients. Iran Red Crescent Med J. 2013:15:e5225.

22. Saadat F, Mahmoudi MR, Rajabi E, Roshan ZA, Shad BM, Karanis P. Seroepidemiology and associated risk factors of Toxoplasma gondii in hemodialysis patients. Acta Parasitol. 2020;65:906-12.

23. Saki J, Khademvatan S, Soltani S, Shahbazian H. Detection of toxoplasmosis in patients with end-stage renal disease by enzyme-linked immunosorbent assay and polymerase chain reaction methods. Parasitol Res. 2013;112:163-8.

24. Hamidi F, Etemadi J, Mehrabani NG, Mahami-Oskouei M, Motavalli R, Ardalan M. Comparison of Toxoplasma gondii seropositivity in hemodialysis and peritoneal dialysis patients. J Coast Life Med. 2015;3:621-2.

25. Khalili B, Mortezaei S, Fazeli M. The comparison of anti-Toxoplasma antibody (lgM, IgG) in hemodialysed patients and those undergoing chemoterapy with healthy blood donor, shahr-E-kord, 1392. Iran J Parasitol. 2015;10:311-311.

26. Rezavand B, Poornaki AM, Mokhtari KR, Mohammad A, Andalibian A Abdi J. Identification and determination of the prevalence of Toxoplasma gondii in patients with chronic renal failure by ELISA and PCR. Asian Pac J Trop Dis. 2016;6:347-9.

27. Dorri M, Dabirzadeh M, Maroufi Y, Afshari M, Chokamy MB. Prevalence of anti-Toxoplasma lgG and IgM in hemodialysis patients comparing to healthy individuals in Sistan area. Iran J Nephropharmacol. 2017;6:106-9.

28. Rasti S, Hassanzadeh M, Soliemani A, Hooshyar H, Mousavi SG, Nikoueinejad $\mathrm{H}$, et al. Serological and molecular survey of toxoplasmosis in renal transplant recipients and hemodialysis patients in Kashan and Qom regions, central Iran. Ren Fail. 2016:38:970-3.

29. Belluco S, Mancin M, Conficoni D, Simonato G, Pietrobelli M, Ricci A. Investigating the determinants of Toxoplasma gondii prevalence in meat: a systematic review and meta-regression. PLoS One. 2016;11:e0153856.

\section{Publisher's Note}

Springer Nature remains neutral with regard to jurisdictional claims in published maps and institutional affiliations.
Ready to submit your research? Choose BMC and benefit from:

- fast, convenient online submission

- thorough peer review by experienced researchers in your field

- rapid publication on acceptance

- support for research data, including large and complex data types

- gold Open Access which fosters wider collaboration and increased citations

- maximum visibility for your research: over $100 \mathrm{M}$ website views per year

At BMC, research is always in progress.

Learn more biomedcentral.com/submissions 